\title{
Analysis of the Effect of Grooves in Single and Twin Axial Groove Journal Bearings under Varying Load Direction
}

\author{
Brito FP ${ }^{\mathrm{a}}$, Miranda $\mathrm{AS}^{\mathrm{a}}$ and Fillon $\mathrm{M}^{\mathrm{b}}$ \\ ${ }^{a}$ Mechanical Engineering and Resource Sustainability Center (MEtRICs), Universidade do Minho, Campus de \\ Azurém, 4800-058 Guimarães, Portugal. \\ ${ }^{b}$ Institut Pprime, CNRS - Université de Poitiers - ENSMA, UPR 3346, Dept Génie Mécanique et Systèmes \\ Complexes, SP2MI, 11 Bd Marie \& Pierre Curie, BP 30179, 86962 Futuroscope Chasseneuil Cedex, France.
}

Keywords: hydrodynamic lubrication; journal bearings; steadily loaded; analytical model

\begin{abstract}
Multi axial groove hydrodynamic journal bearings are often preferred over single grooved ones to improve lubricant distribution. However, when assessing the influence of loading angle for a twin axial groove bearing, the authors detected the occurrence of phenomena such as strong negative flow rate in one of the grooves for a broad range of loading angles which was deleterious to bearing performance. Conversely, single groove bearings display acute starvation for specific loading ranges.

The authors use a previously proposed thermohydrodynamic approach to compare the role of single and twin groove bearings under variable loading direction. Results show that a groove deactivation strategy (using check valves) might be a best-of-both-worlds strategy, optimizing groove flow rate distribution, reducing temperature and eccentricity levels.
\end{abstract}

\section{Introduction}

Hydrodynamic Journal bearings are often used in applications where combinations of high loads and journal surface speeds are present. The lubricant is frequently fed at a prescribed pressure through holes or grooves machined in the bush surface.

Finding the optimal number, geometry and location of feeding grooves relatively to the load line is therefore a valuable task, but it is not a straightforward one. On one hand, the existence of multiple feeding locations along the bush surface may be regarded as desirable in order to provide uniform bearing cooling and lubricant distribution, thus avoiding harmful lubricant starvation. On the other hand, grooves might interfere with the hydrodynamic pressure generation if the hydrodynamic pressure build-up zone gets too close to the vicinity of lubricant feeding grooves and they start acting as pressure sinks instead of pressure sources. This will easily happen if there are multiple grooves [1] or in situations where the load direction might change significantly over time [2]. Further increasing the complexity of this issue is the fact that an excessive increase of lubricant feeding flow rate will eventually lead to the increase of power loss [3][4], an operating parameter which is very sensible in many applications. There is also evidence that sometimes the flow rate distribution for each groove is highly unbalanced [5].

The analyses focusing on the assessment of groove influence on bearing performance are not abundant. In fact, most existing bearing design simulation tools are inadequate to assess this issue as they fail to realistically incorporate lubricant feeding conditions such as feeding pressure, and the actual geometry and location of feeding grooves. This realistic treatment would require the use of mass conserving algorithms which would enable the prediction of film rupture and reformation boundaries as well as the various flow rates crossing the boundaries of the grooves [6][7][8].

The lack of mass conservative algorithms might not be much of a problem in situations where the pressure build-up region is far from the groove regions. However, when grooves start to interfere with the pressure profile, those models will be inadequate as they will not provide a rigorous treatment of groove mixing and other phenomena taking place at the vicinity of grooves. Examples of such complex 
phenomena are the mixing of hot lubricant coming from upstream of the groove with fresh lubricant [9][10] and the occurrence of reverse flow of lubricant re-entering the groove from downstream or the backflow of groove lubricant flowing upstream in the direction opposite to the journal rotation [11][12].

Assessing the performance of journal bearings with multiple grooves under various loading angles clearly needs such a mass conserving and geometrically realistic approach. In fact, some phenomena which cannot be anticipated by conventional approaches have been observed experimentally in twin groove bearings, such as the occurrence of negative flow rate in one groove (see outline in Fig 1), with some of the hot recirculating bearing lubricant flowing from the bearing gap into the groove and then flowing along the feeding piping in the opposite direction. They then mix with the fresh oil which is being fed to the opposite groove and artificially raise the lubricant feeding temperature. This phenomenon was observed under a broad range of load directions, sometimes even when the load was perpendicular to the groove plane (grooves oriented $+/-90^{\circ}$ to the load line) [1][2]. The observation of this phenomenon requires the individual measurement of the flow rate at each groove, something which is not common even in scientific experiments. Such measurements were made only occasionally in the past [13] and more recently by the authors when assessing the role of feeding conditions such as supply temperature [1] and when comparing single and twin axial groove journal bearings with grooves located $+90^{\circ}$ and $+/-90^{\circ}$ to the load line [5]. These studies allowed identifying quite dissimilar behaviour of each groove flow rates when varying load. It was concluded that indeed adding more grooves is not necessarily better in terms of eccentricity and thermal behaviour. For instance, adding an extra groove at $-90^{\circ}$ to the load line did reduce overall bearing temperature but it had the effect of redistributing the lubricant in a quite unbalanced way. Indeed, when adding an extra groove, the total flow rate was kept sensibly the same (it did not increase as it would be expected) and the lubricant fed to the loaded region of the bearing (upstream of the pressure build-up region) was reduced, while the lubricant fed to the unloaded region of the bearing was needlessly increased. These are interesting results albeit obtained for a fixed load direction relatively to the location of the grooves.

The experimental and theoretical efforts done by the team of Gethin and El-Deihi some years ago already hinted at the importance of assessing the combined role of multiple grooves and variable load direction, although their work was focused mainly on high speed twin groove bearings [14][15]. Their predictions were much improved when applying a mixing model for the grooves, but little consideration was made regarding the negative flow rate in a groove and the resulting artificial rise of feeding temperature. Their experiments did not include the measurement of individual groove flow rates either, which limits the analysis of the data.

Recently, measurements were made for a twin groove journal bearing under varying load direction [2]. The major novelty of this work relatively to earlier works seems to be the recording of the individual feeding groove temperatures and flow rates under variable load. It allowed clearly observing the occurrence of negative flow rate over broad ranges of loading directions, accompanied by the artificial rise of the feeding temperature at the opposite groove of the twin groove bearing due to mixing of hot lubricant reflux with fresh lubricant. This happened in situations where the pressure build-up region extended to the vicinity of grooves. These phenomena were successfully replicated in a model developed by the authors [16] where they assessed the influence of load direction on the performance of twin groove journal bearings.

In a later work [17] the influence of deactivating the groove at which negative flow rate was occurring was assessed. A general lowering of the bearing temperature and especially lubricant outlet temperature resulted from the deactivation of the negative flow rate groove. This hints to the fact that there are situations where it may be advantageous to incorporate check valves to each groove feeding line or simply to use a single groove rather than a twin groove journal bearing, but the literature is scarce regarding the comparison of single and twin journal bearings over a wide range of loading directions. Some models have assessed this for single groove [18] and even twin groove bearings [16][19], sometimes for a limited range of load directions, but no results have been published so far comparing single and twin groove journal bearings over a broad range of load vs groove angles. Such work could enable a judicious choice of groove configuration (single/twin) vs load direction but it could also enable to evaluate, to some extent, the merit of groove deactivation through check valves in the 
event of negative flow rate. The present work extends the previous analysis of twin journal bearings under variable load direction to include a comparison of this geometry with single groove bearings.

\section{Theoretical model outline}

The bearing analysis tools is the same as the one already described in previous works [16][20].

Therefore, only a brief outline of the model is now provided.

- The model implements a full Thermohydrodynamic (THD) approach, with a realistic treatment of the lubricant supply conditions. For instance, it takes into account the actual lubricant feeding pressure, and temperature and the specific dimensions of the grooves.

- The Generalized Reynolds Equation is used to solve the hydrodynamic pressure field by means of a control volume method that has been inspired in the algorithm proposed by Elrod [21], which has been adapted to the full THD approach and has been further refined.

- The Energy Equation, which governs viscous dissipation and heat transfer within the fluid is solved through a semi-implicit finite difference scheme. Variable lubricant viscosity was considered to occur across the thickness of the film.

- The Laplace equation is used to solve the heat conduction problem within the bush body through a finite difference Successive Over-Relaxation method.

- Special treatment is given to the groove regions by means of a highly detailed thermal balance in which all the heat fluxes that are relevant for the problem are taken into account: convective heat transfer between the bush body and the groove oil, effect of the hot oil reaching the trailing edge of the grooves from upstream, reverse flow reaching the leading edge of the grooves from downstream, lubricant back flow flowing towards upstream of the trailing edge of the grooves and lubricant feeding flow. A mixing coefficient is also introduced. It is used to differentiate the effective temperature of each of the outbound lubricant flows (axial flow, leading edge flow, trailing edge back flow, if existent) defining the extent to which the lubricant fed to the next bearing land mixes with existing groove lubricant. The mixing coefficient is not used as an alternative to the groove region energy balance (the model is energy conservative). It is rather used to differentiate the average temperature of each one of the groove outbound fluxes. A low mixing degree of hot oil with groove oil provided the best correlation with experimental results.

- Mathematical curves for the temperature profile of the inlet section are applied. Usually they were based on an exponential expression with the form $T(y)=T_{\text {bush }}+\left(T_{\text {shaft }} T_{\text {bush }}\right)^{*}\left(e^{C y}-1\right) /\left(e^{C}-1\right)$. This expression yields temperature values across the thickness which vary continuously between the local bush surface temperature, $T_{\text {bush, }}$ and the shaft temperature, $T_{\text {shaft. }}$ The coefficient $C$ is calculated so that the resulting effective temperature corresponds to the effective inlet section temperature, $T_{\text {is }}$, calculated from the heat balance made to the groove region. When $T_{\text {is }}$ was not between $T_{\text {bush }}$ and $T_{\text {shaft, }}$, a quadratic profile would be used.

- The ruptured film region (often called the cavitated region) is modelled through a modified Effective Length concept incorporating the influence of a shaft-adhered lubricant layer that has been observed experimentally. This is an improved version of the model proposed by Knight and Ghadimi [22] and takes advantage of the knowledge of the local liquid fraction provided by the film rupture model.

- The thermal expansion of the components is modelled using the simplified differential thermal expansion approach.

The model has been extensively validated in previous works, including a validation for variable load direction results.

Fig 2 displays an outline of the main bearing geometric parameters.

\section{Results and discussion}

Prior to the presentation of the results a table with the main bearing geometric characteristics, operating and feeding conditions and lubricant properties used in the simulations is presented in Tab 1. All simulation conditions are identical to those used in [16] for the twin groove bearing. The geometry and the lubricant properties were based on an experimental work [4] with a few exceptions (slight different clearance and feeding pressure). It is worthy of mention that the load angle was allowed to vary for the whole $360^{\circ}$ range, for applied loads between 0.2 and $4 \mathrm{MPa}$, although not all simulations could be completed due to lack of load capacity in some cases. Fixed eccentricity 
simulations were also performed for a broad range of variation this parameter (usually between 0.1 and 0.93).

The first results to be analyzed are those related to the midplane hydrodynamic pressure profile along the circumferential direction, for a low $(0.2 \mathrm{MPa})$ and a medium (1 MPa) specific load case and for several load angles (Fig 3).

If we exclude the differences in the circumferential location of the pressure build up region due to the definition of the origin, the main differences between all pressure profiles are mostly linked to the interference of grooves in the hydrodynamic pressure generation process.

It may be seen that the closer the pressure build-up region is to a groove, the higher the impact it has in terms of pressure profile destabilization and increase of maximum pressure. It may be seen that this effect is quite strong for a twin groove bearing with $\Gamma=0^{\circ}$ (Fig 3a) because groove 2 is located right in the midst of the pressure generation region. Indeed, for Ws $=1 \mathrm{MPa}$ the twin groove bearing displays a maximum pressure which more than doubles the value of the single groove one. The results for these conditions may be better appreciated for the whole length of the bearing (not just the midplane) by looking at Fig 4.

By further inspecting Fig 3, it may be seen that when both grooves are kept away from the pressure build-up region (as in the case $\Gamma=90^{\circ}$ ), the twin groove bearing profile becomes very similar to the single groove one. It is interesting to note in Fig 4 that the horizontal gridlines corresponding to the 0 bar level and drawn in the single groove bearing pressure profile denote the film rupture and reformation boundaries (the two horizontal curved gridlines drawn downstream of groove 1). It may be seen that in the case of twin groove bearing, no film rupture/reformation boundaries exist since no 0 bar gridlines are visible in this same region.

The evolution of lubricant feeding flow rate with load angle may be observed in Fig 5 for several specific loads. These are perhaps the most insightful results of the simulation, as they enable a deeper perception of many of the bearing performance parameters. Fig $5 \mathrm{a}$ and Fig $5 \mathrm{~b}$ refer to the total flow rates for the single and twin groove geometry, respectively. The latter is a result from the combination of the flow rates of groove 1 (Fig $5 \mathrm{c}$ ) and groove 2 (Fig $5 \mathrm{~d}$ ). One important feature of the single groove bearing flow rate behaviour is that it tends to zero in the vicinity of $\Gamma=180^{\circ}$. Actually, when performing simulations for fixed eccentricity the range of specific load capacities achieved was very low, even lower than the lowest specific load of the graphs $(\mathrm{Ws}=0.2 \mathrm{MPa})$ and the temperature achieved were very high. This means that even a mildly loaded single groove bearing might suffer severe lubricant starvation and seizure should the load angle get close the $180^{\circ}$ range.

Fig $5 b$ shows that the twin groove bearing never achieves the acute starvation suffered by the single groove one at $\Gamma$ around $180^{\circ}$. The total flow rate is generally above $11 / \mathrm{min}$. This is explained by the fact that even if a groove is located right in the midst of the pressure build-up region with acute negative flow rate there will always exist another groove feeding the bearing.

It is quite interesting to observe the behaviour of each one of the grooves of the twin groove bearing. There are broad ranges of load angles where the flow rate is negative in one of them. Due to symmetry reasons, it is not difficult to note that their behaviour is identical but with an offset of $180^{\circ}$.

The reason for the negative flow rate, already explored in a previous publication [16] is that the feeding system works at a constant feeding pressure (1bar gauge pressure) and therefore the groove might act either as a lubricant source or a lubricant sink depending on the pressure gradient in the vicinity of the grooves (recall Fig 1). For instance, it is clear in Fig 3a that the strong pressure gradients around groove 2 for $\Gamma=0$ 을 are responsible for inducing the negative flow rate of groove 2 observed in Fig $5 \mathrm{~d}$. The behaviour of groove flow rates is fundamental to understand other bearing performance parameters, as will be seen further ahead. 
An interesting alternative way of analysing flow rate is to assess it as a function of specific load (Fig 6). Here the twin groove bearing was compared against bearings with a single groove located at the position of groove 1 or groove 2. It can be seen that even for a given load angle the flow rate distribution among grooves may vary significantly. It may be seen that increasing the load may sometimes increase or decrease the flow rate, and induce or eliminate negative flow rate in one of the grooves of the twin groove bearing. This has to do with the effect which load variation has on approximating or withdrawing the pressure build-up region from the vicinity of that groove. The effect which negative flow rate in a groove has on the artificial rise of the lubricant feeding pressure at the opposite groove due to mixing of refluxing lubricant with fresh lubricant is also interesting but it has been already reported in [16] for the same simulation conditions, so it is not presented here. The resulting specific load capacity range of the single groove bearing with $\Gamma=180^{\circ}$ was so low (always below 0.04 for eccentricities between 0.1 and 0.9 ) that it is not seen in Fig 6a.

The effect which load angle has on eccentricity may be seen in Fig 7 for several loads and for the single and twin groove configurations. Regarding single groove bearings (Fig 7a), eccentricity is fairly low for a broad range of load angles, but it starts to increase abruptly when approaching $180^{\circ}$. For load angles around this value, the load capacity drops so much that when simulating this bearing geometry with fixed eccentricity the specific load capacities obtained were below $0.04 \mathrm{MPa}$, that is, always lower than even the lowest specific load of the figure $(\mathrm{Ws}=0.2 \mathrm{MPa})$. The explanation for this has to do with the exceptionally low feeding flow rates resulting from these operating conditions (Fig 5a) which cause lubricant starvation and extreme lubricant temperatures, as discussed further ahead.

Regarding the twin groove bearing (Fig $7 \mathrm{~b}$ ), the eccentricity is maximized for load angles between $0^{\circ}$ and $45^{\circ}$ (and of course between $180^{\circ}$ and $225^{\circ}$ for symmetry reasons). However, with this groove geometry it was possible to achieve convergence for the whole range of load angles with specific loads up to $1 \mathrm{MPa}$. This is because there is always another groove compensating for the low (or even negative) flow rate in the other one. It may be seen that eccentricity ratio of the twin groove bearing is normally lowest within the region where the flow rate is positive in both grooves. Since for a given value of specific load the variation of eccentricity with the load angle reflects the capability of the bearing to support the applied load, it seems that avoiding negative flow rate in a groove may be beneficial for bearing performance.

Values for maximum bush temperature $\left(T_{\max }\right)$ are presented in Fig 8 for both bearing geometries. It may be seen that they roughly follow the evolution of eccentricity (Fig 7) and their trend is roughly the inverse of the total flow rate trend (Fig 5a, Fig 5b). This makes perfect sense because one of the roles of lubricant flow is to cool down the bearing. The twin groove bearing generally operates cooler than the single groove one, because of this, except for load angles around $0 \% 360^{\circ}$. Under this range, there is a strong hot oil reflux in one of the grooves which artificially rises the feeding temperature at the opposite groove (as sketched in Fig 1), thus globally raising the temperature level of the bearing.

The bush/lubricant interface temperature profiles at the midplane of the bearing are presented in Fig 9 comparing single and twin groove bearings for several loads and load angles. The profile discontinuities around $0^{\circ}$ and $180^{\circ}$ correspond to the inner groove temperature.

It may be observed that the cooling effect of grooves (the temperature fall across the groove regions) is proportional to the lubricant flow rate at the corresponding groove (recall Fig 5). There are situations where the effect of adding an extra groove to a single groove bearing is quite apparent in terms of cooling. This is clearly seen in situations where the groove of a single groove bearing is hardly providing any lubricant, such as in the cases of $\Gamma=120^{\circ}$ or $240^{\circ}$ (compare Fig 5 with Fig $9 \mathrm{~d}, \mathrm{e}$ ). Twin groove bearings can also operate hotter than single groove ones, as in the case Fig 9f. This is so because the extra groove added did not contribute to increase lubricant flow rate. On the contrary, negative flow rate occurred at that groove, as seen in Fig 5c). 
Fig 10 displays the comparison of single and twin groove bearing power loss. It is approximately inversely proportional to flow rate because the increase of the presence of lubricant within the bearing gap also tends to increase drag. Reducing drag by tuning the groove angle of single groove bearings would imply allowing for an eccentricity increase. So a tricky trend-off must be made between the effort of reducing power loss while avoiding an excessive rise of the eccentricity, maintaining it within safe limits. Regarding twin groove bearings, their minimum power loss more or less coincides with the minimum of the eccentricity, so it seems easier and safer to optimize their operation for minimum drag. Nevertheless, their window of efficient operation is somewhat narrow, corresponding roughly to the positive flow rate range as already noted.

It seems that single and twin groove bearings display load angle ranges where one is more advantageous than the other. Namely, it seems that the twin groove bearing displays a good performance when no negative flow occurs in any of the grooves. On the other hand, single groove bearings with a groove located either to the upstream of the load line or the downstream of the load line will perform better than the twin groove bearing when negative flow rate is present in one of its grooves.

Now, deactivating a groove where negative flow rate is occurring is somewhat similar to swapping a twin groove bearing for a single groove bearing with a groove located in the same place as the twin groove bearing's positive flow rate groove. Of course, there will be some differences between a twin groove bearing with a deactivated groove and a single groove bearing since the latter will have a thin bearing clearance/film at the same location where the former has an inactive groove pocket in which no hydrodynamic pressure may be generated due to the lack of a thin convergent lubricant film. However, adding a check valve to a groove in which negative flow rate was occurring will not only eliminate any feeding flow rate but it will also allow the groove to stop acting as a pressure sink and a lubricant sink. Probably, the resulting pressure profile of a twin groove bearing with check valves in its grooves will be something between the twin groove profile and the single groove profile represented previously in Fig 4. Probably the inactive groove cavity will eventually change its pressure until no flow exists across its borders. In the case of $\Gamma=0^{\circ}$ it will probably increase the pressure above the feeding pressure and reduce the pressure peak observed in the case of the twin groove bearing because there is no longer a pressure and lubricant sink, but only a region of fairly uniform pressure where no hydrodynamic lift exists.

The effect of an inactive groove might be satisfactorily simulated by artificially increasing the feeding pressure of a groove where negative flow rate is occurring until the mass balance across all groove region boundaries provides no net flow rate into or out of the groove region. The resulting feeding pressure would thus be the stabilized inner groove pressure resulting from the occlusion of the negative flow rate by the check valve.

In the absence of such a modelling, and in order to assess what might be the effect of adding check valves to each one of the twin grooves of a bearing, it seems useful to approximate it to a single groove bearing whenever negative flow rate is present, as depicted in Fig 11 . For instance, performing an overlap of the eccentricity results of the single and twin groove bearings of Fig $12 \mathrm{a}$, provides the idealized bearing results of Fig $12 \mathrm{~b}$. This and the subsequent figures represent what would be an optimal system in which the groove under negative flow rate is eliminated. The bearing sketch with one of the grooves filled in red means that groove has been eliminated/deactivated for that load angle range. A twin groove bearing with check valves would have a behaviour which might resemble these results, although not perfectly due to the absence of hydrodynamic pressure generation within the deactivated groove region. The results of eccentricity presented in Fig $12 \mathrm{~b}$ indicate a much more stable operation with varying load angle than either of the single or twin groove configurations. The dotted lines were kept to indicate the approximate boundary of negative flow rate inception in the twin groove bearing. These results might be similar to what would be expected of a bearing in which the grooves would not affect flow rate. Such bearing performance would be totally independent of load angle. 
The single/twin groove curve overlapping results of maximum pressure, maximum bush temperature and power loss of the idealized bearing which supresses a groove whenever it displays negative flow rate may be seen in Fig 13 and compared against Fig 8 and Fig 10 for the unchanged single and twin groove bearings.

Regarding maximum pressure (Fig 13a) the pressure peaks of twin groove bearings around $0 \% 180^{\circ}$ (Fig 3a) have been suppressed. Maximum bush temperature (Fig 13b) peaks of single and twin groove bearings observed in Fig 8 have been palliated.

With power loss there are mixed results. Depending on the range, there are power loss increases or decreases. Nevertheless, the increases in power loss usually indicated a beneficial reduction in eccentricity, with the bearing being now able to operate at the whole load angle range.

\section{Conclusions}

A thermohydrodynamic analysis comparing the performance of single and twin groove journal bearings under variable load angle $(\Gamma$, the angle between the load line and the plane defined by the midline of the grooves) has been carried out. An existing model incorporating realistic lubricant feeding conditions such as the feeding pressure and the actual dimensions of feeding grooves has been used for this purpose.

The robustness of the model has been reassured as it was able to attain convergence and predict the main bearing performance parameters for a wide range of loads and load angles. This included operating conditions where strong reverse flow and even negative flow rate in one of the grooves was occurring, namely in situations where a groove was right in the midst of a pressure build-up region. The model seems suitable to treat this kind of phenomena in a robust way since it incorporates detailed mass- and energy-conservative models for the groove mixing and for the film rupture and reformation phenomena. The following conclusions can be drawn:

i) The variation of load angle deeply affects the bearing performance when interference of grooves with the hydrodynamic pressure generation process takes place. This causes a strong reduction of lubricant flow rate entering the groove involved;

ii) The consequences of this reduction in flow rate were especially acute in the case of a single groove bearing for load angles in the $120^{\circ}-270^{\circ}$ range. Under such conditions lubricant renewal would become so low that it could induce excessive lubricant temperature, acute loss of lubricant viscosity and eventually loss of any relevant load carrying capacity;

iii) Twin groove bearings are able to maintain, under all operating conditions, a lubricant feeding capability ensuring lower operating temperature than single groove bearings and some load carrying capacity;

iv) Lubricant feeding distribution in twin groove bearings can be highly unbalanced. Negative values of lubricant flow rate in one of the grooves (the one located in the active region) can occur for a broad range of loads and load angles, this being deleterious for bearing performance. The elimination of the negative flow rate groove was found to be positive for bearing performance;

v) In a real bearing the elimination of negative flow in feeding grooves can be achieved using check valves in the feeding pipes. The twin groove bearing with groove deactivation in case of negative flow rate would be the best configuration for every range of loads and load directions, being able to adapt its feeding conditions to the operating conditions. 


\section{Acknowledgements}

Francisco P. Brito currently benefits from Postdoctoral grant SFRH/BPD/89553/2012, financed by FEDER funds through Programa Operacional Fatores de Competitividade - COMPETE and National funds through PIDDAC and FCT - Fundação para a Ciência e a Tecnologia; he has also received support from Luso-American Foundation / National Science Foundation (FLAD/NSF) 2013 PORTUGAL - U.S. Research Networks Program.

\section{References}

[1] Brito FP, Miranda AS, Claro JCP Fillon M. (2011) The Role of Lubricant Supply Temperature on the Performance of Twin Groove Journal Bearings: An Experimental Study. International Journal of Surface Science and Engineering, Inderscience Publishers, 5(4), 286-299. DOI: 10.1504/IJSURFSE.2011.044278.

[2] Arab Solghar A, Brito FP, Claro JCP, Nassab AG. (2011) An experimental study of the influence of loading direction on the thermohydrodynamic behavior of twin axial groove journal bearing. Proceedings of the Institution of Mechanical Engineers Part J: Journal of Engineering Tribology, 225(5), 245-254; DOI 10.1177/1350650111401970.

[3] Costa L, Fillon M, Miranda A, Claro JCP. (2003), An Experimental Investigation of the Effect of Groove Location and Supply Pressure on the THD Performance of a Steadily Loaded Journal Bearing. ASME Journal of Tribology, 122, pp. 227-232.

[4] Brito FP, Bouyer J, Fillon M, Miranda AS. (2007) Experimental Investigation of the Influence of Supply Temperature and Supply Pressure on the Performance of a Two Axial Groove Hydrodynamic Journal Bearing. ASME Journal of Tribology, 129, pp. 98-105.

[5] Brito FP, Miranda AS, Claro JCP, Fillon M. (2012) Experimental Comparison of the Performance of a Journal Bearing with a Single and a Twin Axial Groove Configuration, Tribology International, Elsevier, 54 (2012) 1-8.

[6] Dowson D, Taylor CM, Miranda AS. (1985), The prediction of liquid film journal bearing performance with a consideration of lubricant film reformation, part I and II., Proc. IMechE, Vol 119, C2, pp. 95-102, 102-111.

[7] Braun MJ and Hannon WM "Cavitation formation and modelling for fluid film bearings: A review" Proceedings of the Institution of Mechanical Engineers, Part J: Journal of Engineering Tribology, 224(9), 839-863.

[8] Costa L, Miranda AS, Fillon M, Claro JCP. (2003) An analysis of the influence of oil supply conditions on the Thermohydrodynamic performance of a single groove journal bearing. Proc. Inst. Mech. Engs., Part J: Journal of Engineering Tribology, Vol. 217, pp. 133-144.

[9] Kosasih PB \& Tieu AK. (2004) An investigation into the thermal mixing in journal bearings. Proc. Instn Mech. Engrs Vol. 218 Part J: J. Engineering Tribology, pp. 379-389.

[10] Jeddi L, El Khlifi M \& Bonneau D. (2005) Thermohydrodynamic analysis for a hydrodynamic journal bearing groove. pp. 263-274.

[11] Groper M, Etsion I, (2002) Reverse flow as a possible mechanism for cavitation pressure build-up in a submerged journal bearing. ASME Journal of Tribology, 124:320-6.

[12] Pinkus O. (1990) Thermal Aspects of Fluid Film Tribology. ASME Press, New York.

[13] Basri H. and Neal P.B. (1990) Oil flow in axial groove journal bearings. In Proceedings of the Seminar on Developments in Plain Bearings for the '90s, IMechE Tribology Group, May 1990, pp. 1117 (Mechanical Engineering Publications, London). 
[14] Gethin DT, \& El-Deihi, MKI. (1990), Thermal behavior of a twin axial groove bearing under varying loading direction. Proc. IMechE, Part C. 204, pp. 77-90.

[15] El-Deihi MKI \& Gethin DT. (1992) A Thermohydrodynamic Analysis of a Twin Axial Groove Bearing Under Different Loading Directions and Comparison With Experiment. ASME Journal of Tribology, 114, pp. 304-310.

[16] Brito FP, Fillon M, Miranda AS, Costa L, Claro JCP, Teixeira JC (2014) "Thermohydrodynamic Modelling of Journal Bearings under Varying Load Angle and Negative Groove Flow Rate", Proceedings of the Institution of Mechanical Engineers Part J: Journal of Engineering Tribology, 228(9) 955-973.

[17] Arab Solghar A, Brito FP, Claro JCP (2014) An experimental investigation on the influence of deactivation of a groove on the performance of a twin groove journal bearing, Proceedings of the Institution of Mechanical Engineers Part J: Journal of Engineering Tribology, Sage, 228(5): 548-557, DOI: $10.1177 / 1350650113518521$

[18] Roy L (2009) Thermo-hydrodynamic performance of grooved oil journal bearing, Tribology International 42 1187-1198.

[19] Kumar DV, Chand S \& Pandey KN (2014) Effect of the groove dimensions and orientation on the static and dynamic performance of non recessed hybrid journal bearing. In H Selvaraj, D Zydek \& G Chmaj (Eds), Progress in Systems Engineering, pp 555-561. Springer International Publishing, ISBN 978-3-319-08422-0.

[20] Brito FP, Fillon M, Miranda A S, Costa L, Claro JCP, Teixeira JC. (2014), The role of lubricant feeding conditions on the performance improvement and friction reduction of journal bearings, Tribology International, 72, pp. 65-82, http://dx.doi.org/10.1016/j.triboint.2013.11.016.

[21] Elrod HG. (1981) A cavitation algorithm, ASME Journal of Lubrication Technology, 103, no 3, 350354.

[22] Knight JD \& Ghadimi P. (1992) Effects of modified Effective length models of the rupture zone on the analysis of a fluid journal bearing, STLE Tribology Transactions, Vol.35, pp 29-36. 

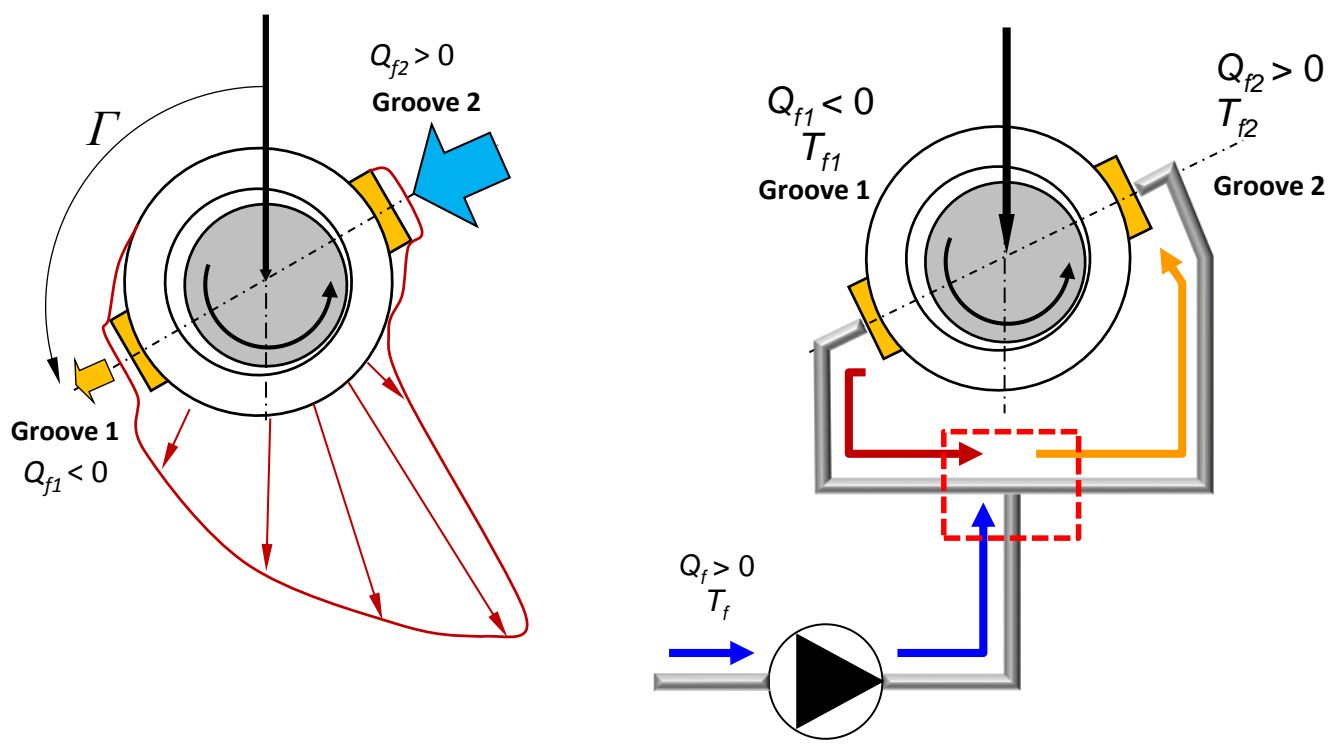

Fig 1 - Outline of the mechanism of negative feeding flow rate (a); occurrence of negative flow rate at Groove 1 causes an effective rise of the feeding temperature at Groove 2 due to mixing of hot oil with fresh lubricant. 


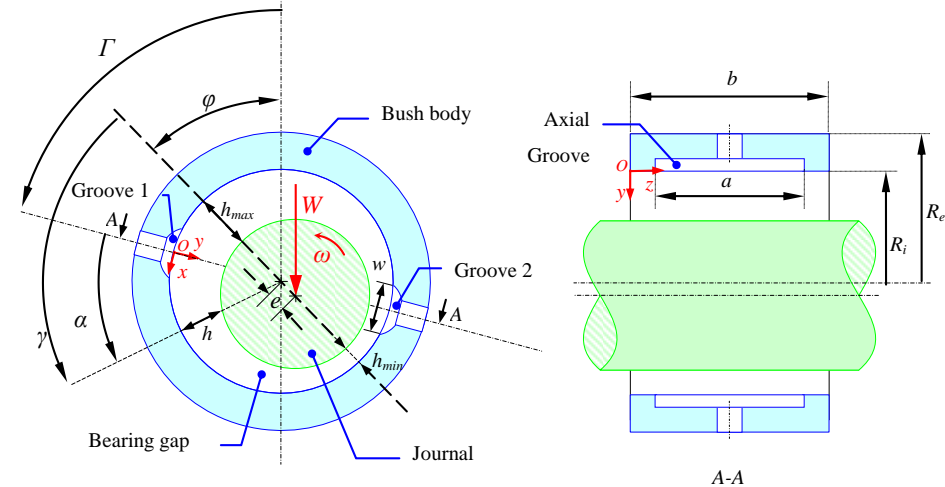

Fig 2 - Outline of the bearing geometric parameters. 


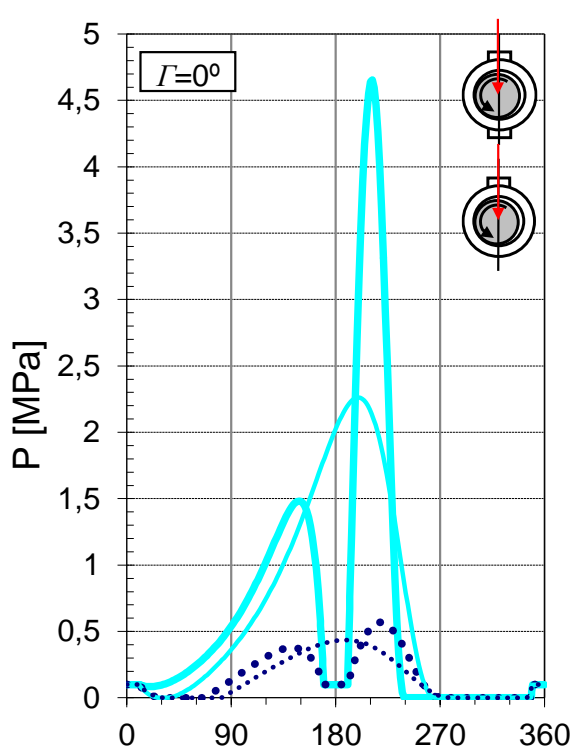

Angle from centre of Groove $1[\stackrel{0}{ }]$

(a)

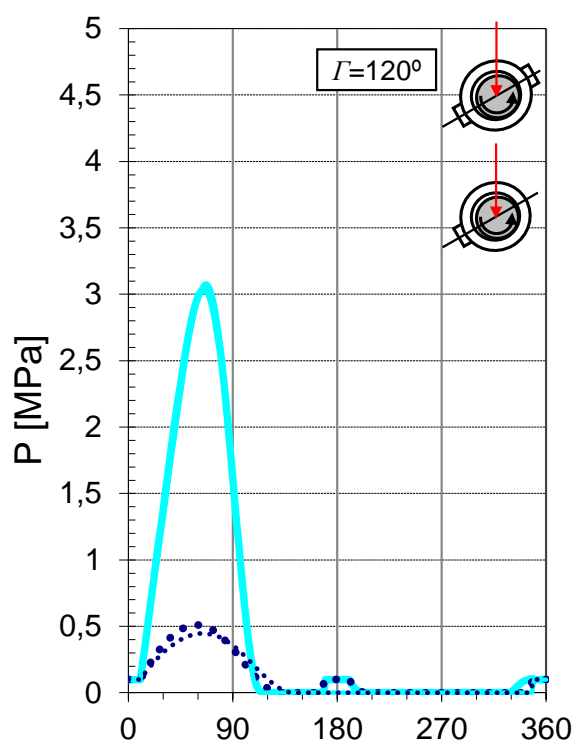

Angle from centre of Groove 1 []

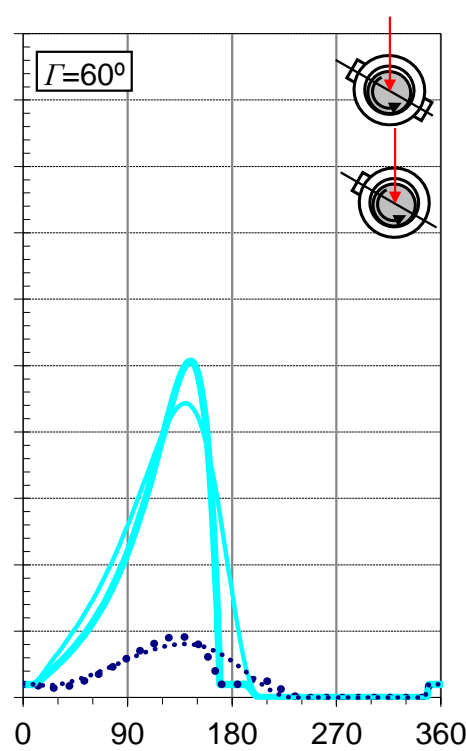

Angle from centre of Groove 1 [우

(b)

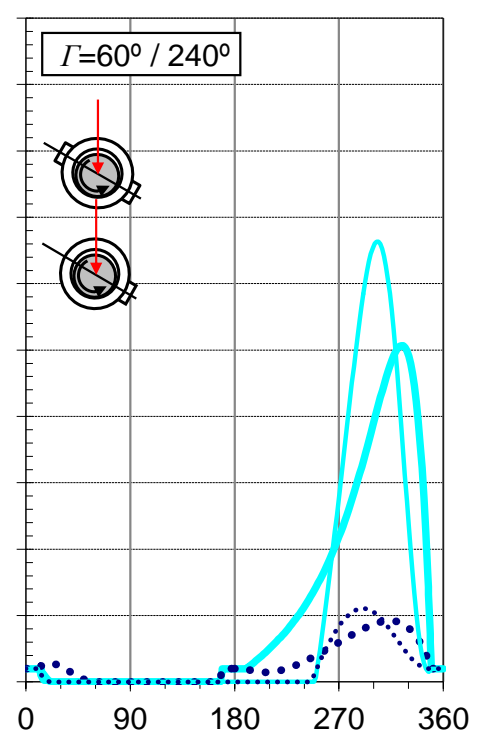

Angle from centre of Groove 1 [ํㅜ

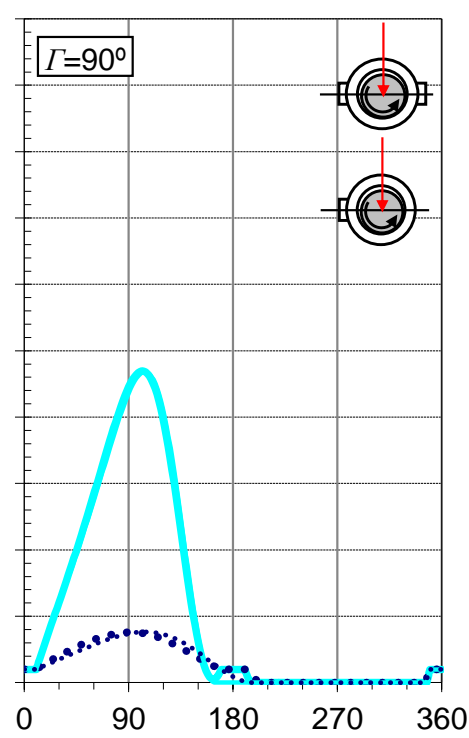

Angle from centre of Groove 1 [] $^{\circ}$

(c)

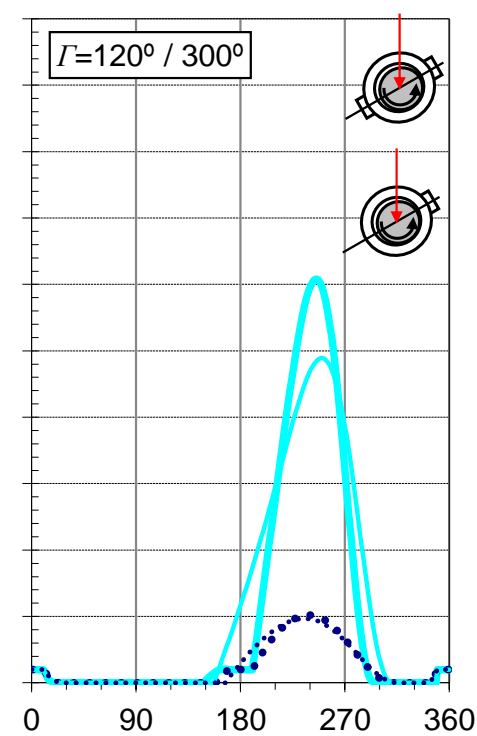

Angle from centre of Groove 1 [으

$\mathrm{Ws}=1 \mathrm{MPa}$ single Ws $=1 \mathrm{MPa}$ twin

$\mathrm{Ws}=0.2 \mathrm{MPa}$ single

Ws $=0.2 \mathrm{MPa}$ twin

Fig 3-Hydrodynamic pressure profiles at the midplane of the bearing, along the circumferential direction for a low $(0.2 \mathrm{MPa})$ and a medium (1 MPa) specific load case and for several load angles. 


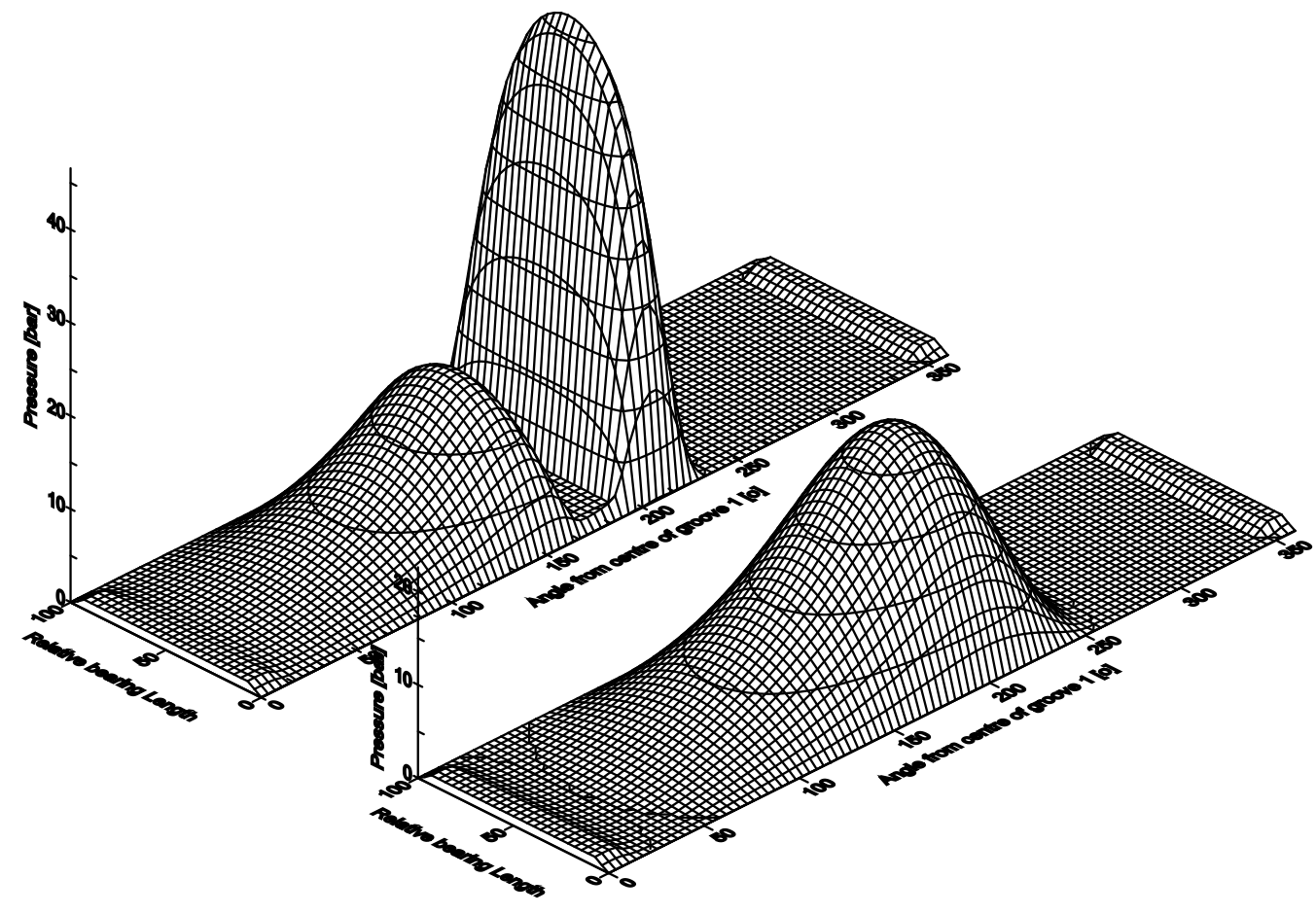

Fig 4 - Hydrodynamic pressure profiles of a single (right) and a twin (left) groove bearing for a medium (1 MPa) specific load and for $\Gamma=0^{\circ}$. 


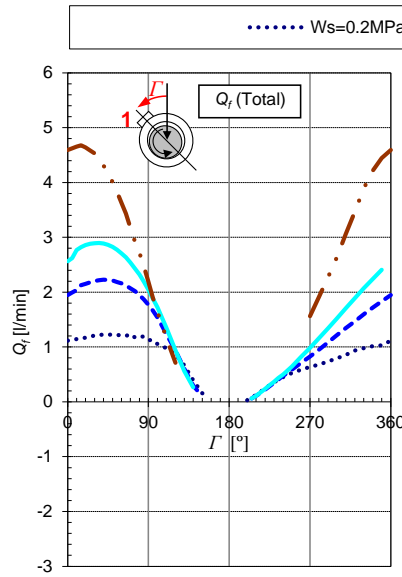

(a)

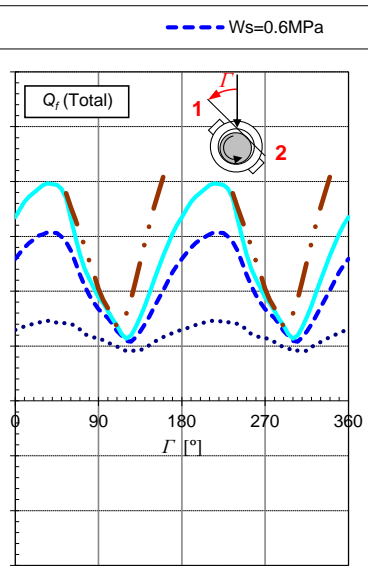

(b)

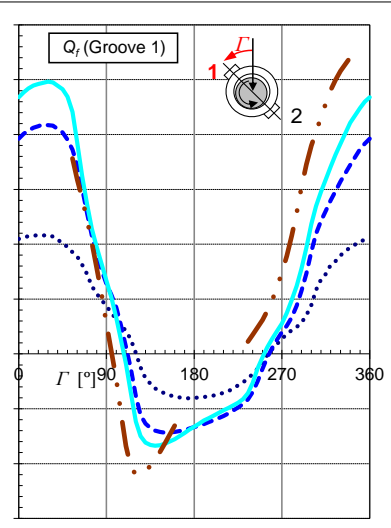

(c) $-\cdot \mathrm{Ws}_{\mathrm{s}}=\mathrm{MPa}$

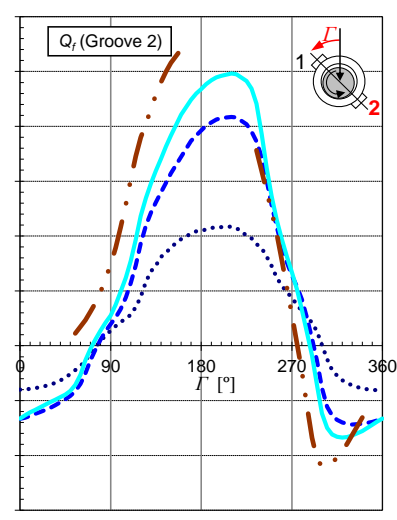

(d)

Fig 5 - Total flow rate as a function of load angle for (a) a single and (b) a twin groove bearing; Partial flow rates at (c) groove 1 and (d) groove 2 of a twin groove bearing. 


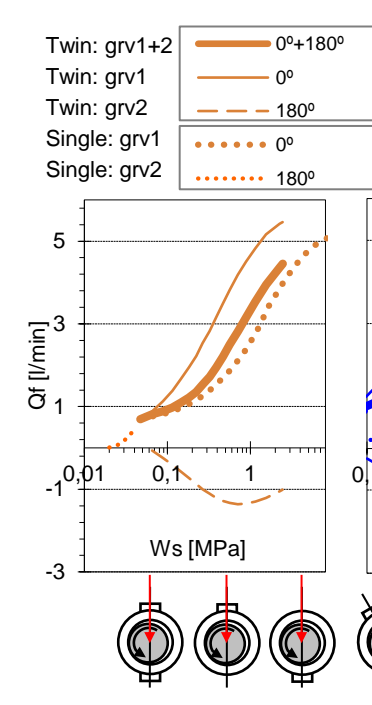

(a)
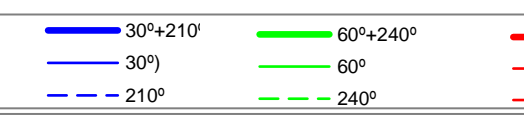

..... $30^{\circ} \quad \cdots \cdots 60^{\circ}$
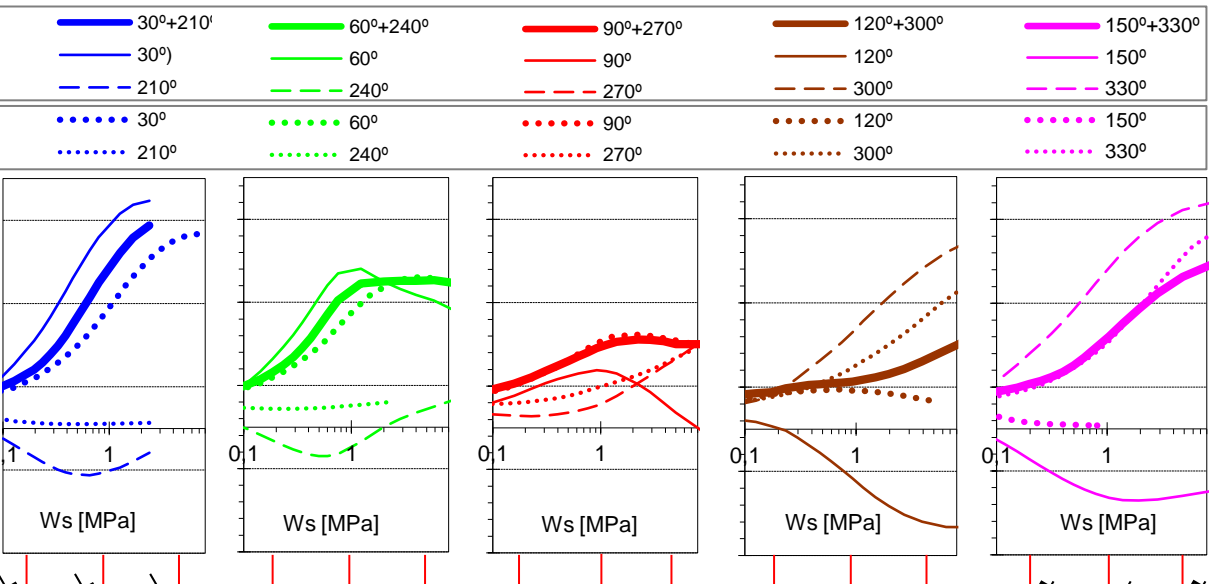

(4) (2)

(b) (c) (d)

(e)

(f)

Fig 6 - Total and partial (groove) flow rates of single and twin groove bearings as a function of specific load for 6 different load angles. 


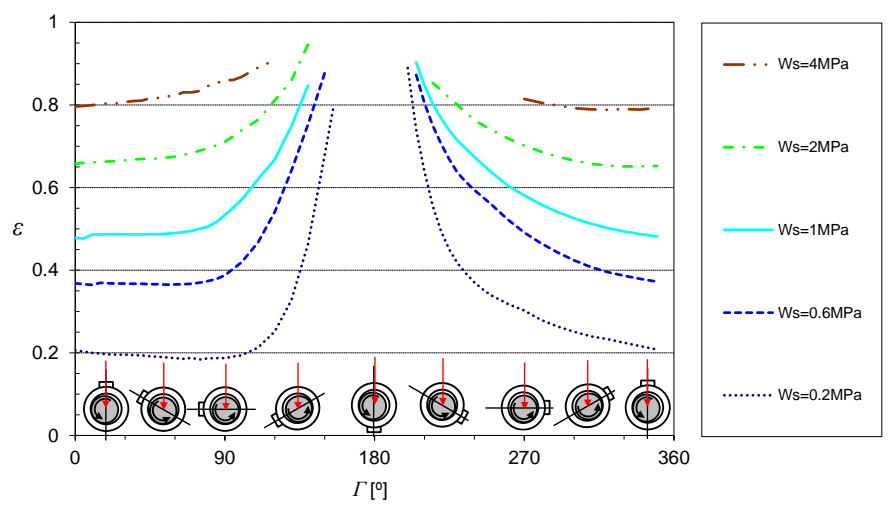

(a)

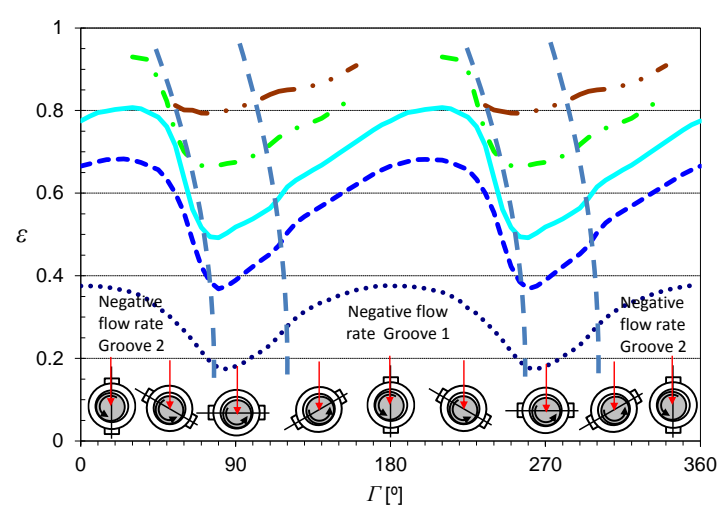

(b)

Fig 7 - Eccentricity ratio as a function of load angle for (a) a single groove and (b) a twin groove journal bearing. 


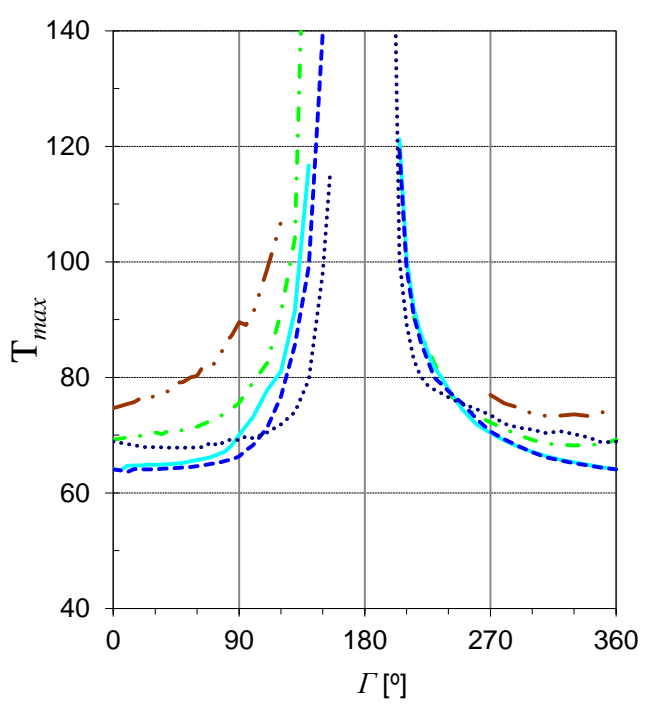

(a)

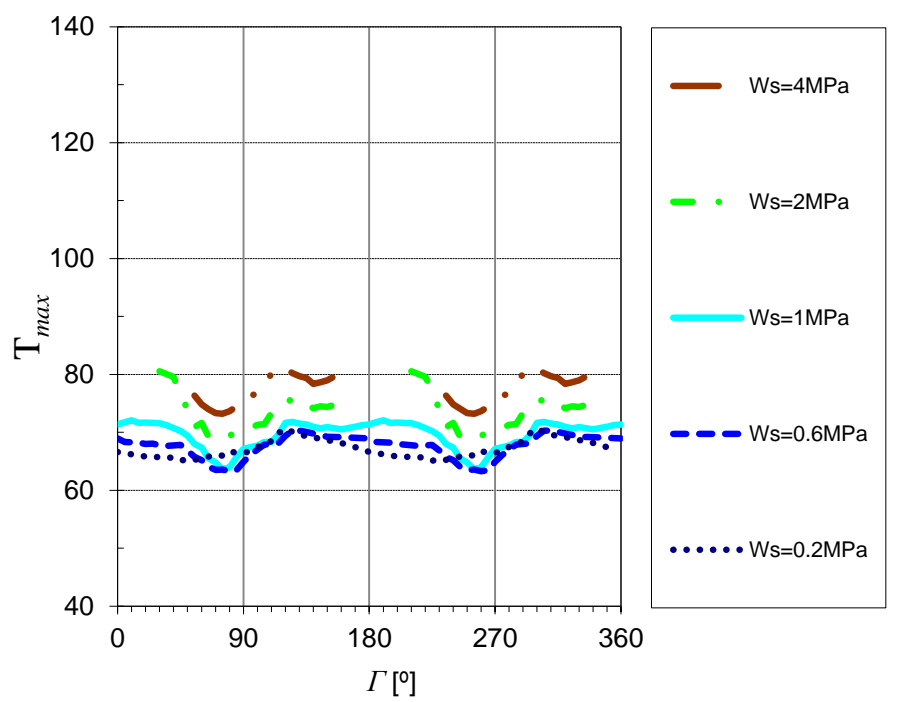

(b)

Fig 8 - Maximum bush temperature as a function of load angle for (a) a single groove and (b) a twin groove journal bearing. 


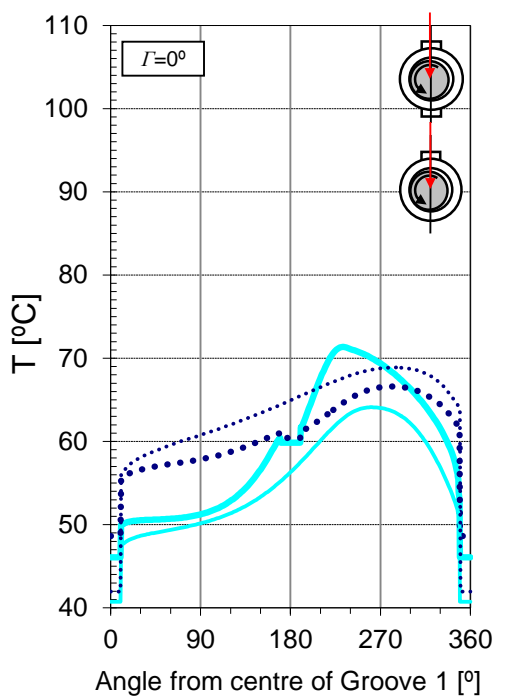

(a)

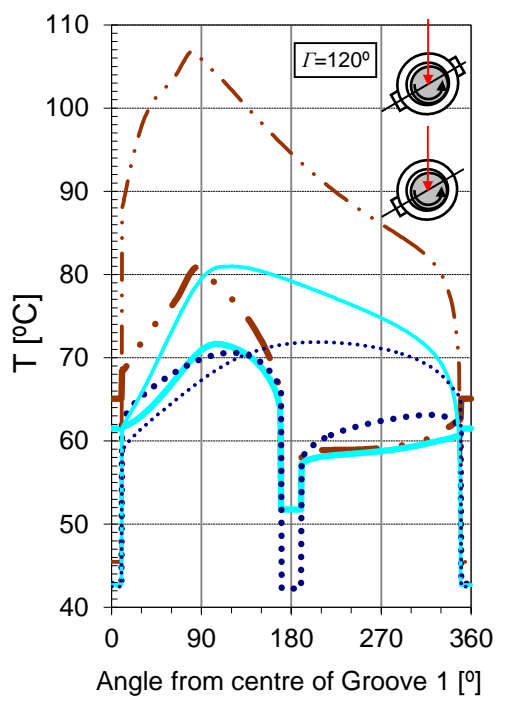

(d)

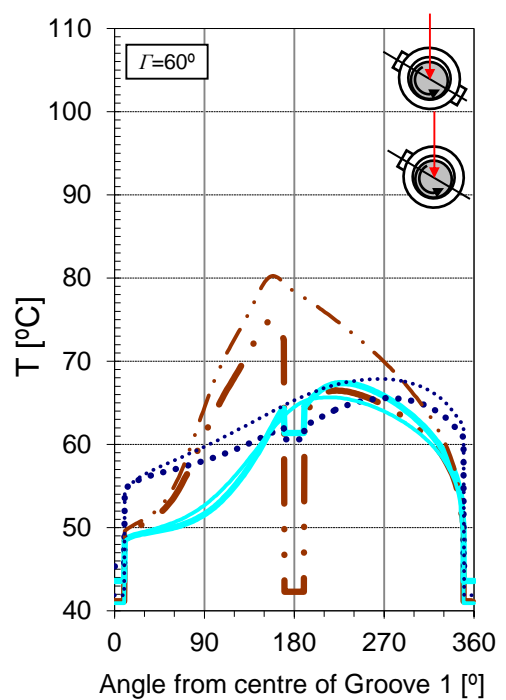

(b)

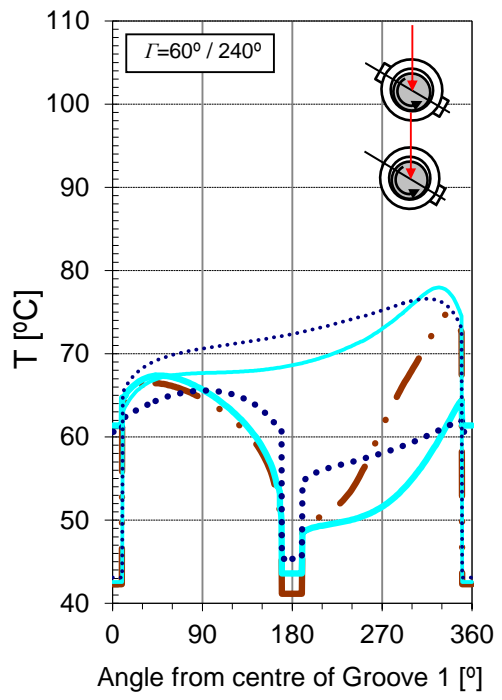

(e)

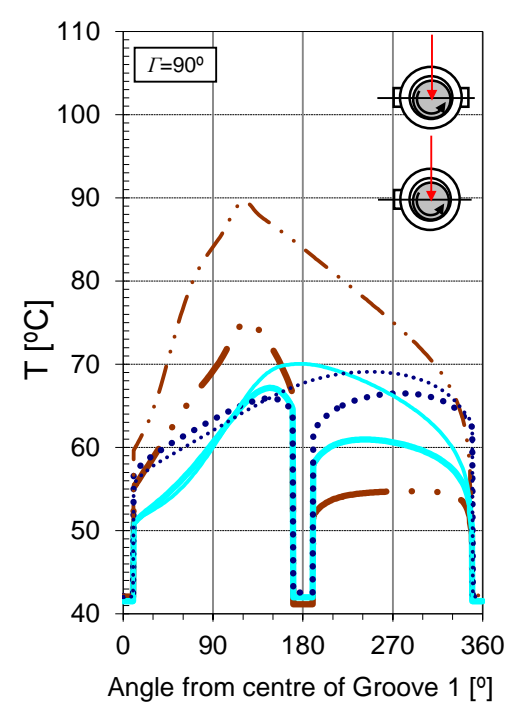

(c)

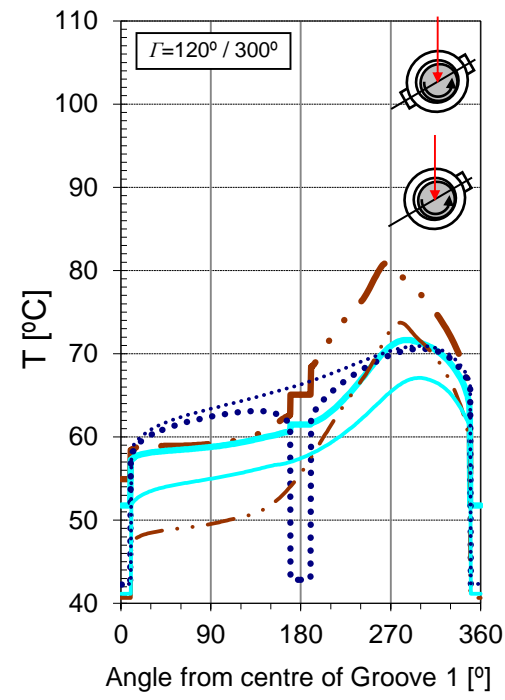

(f)

$\ldots \ldots W \mathrm{~W}=0.2 \mathrm{MPa}$ Single
$\cdots \cdots \mathrm{Ws}=0.2 \mathrm{MPa}$ Twin

$W \mathrm{~W}=1 \mathrm{MPa}$ Single
$W \mathrm{~s}=1 \mathrm{MPa}$ Twin

- WWs $=4 \mathrm{MPa}$ Single

Ws=4MPa Twin

Fig 9 - Inner bush temperature profiles at the midplane of the bearing, along the circumferential direction for a low $(0.2 \mathrm{MPa})$ and a medium $(1 \mathrm{MPa})$ specific load case and for several load angles. 


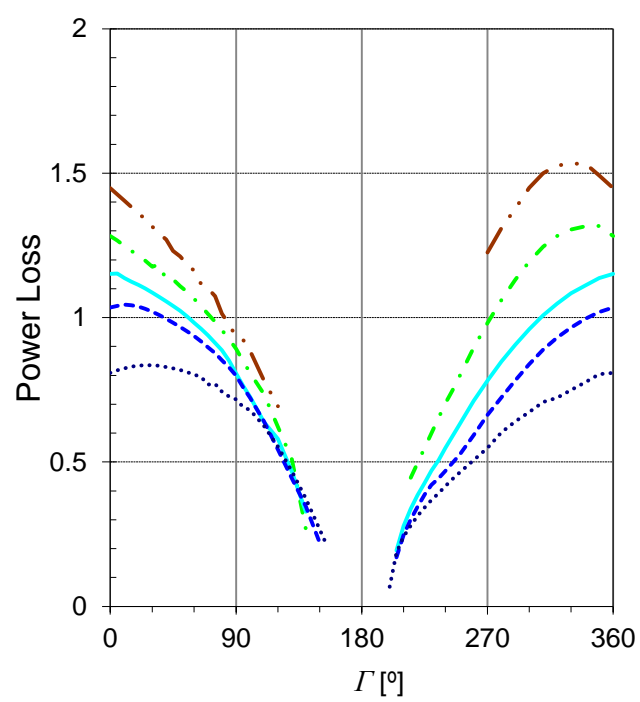

(a)

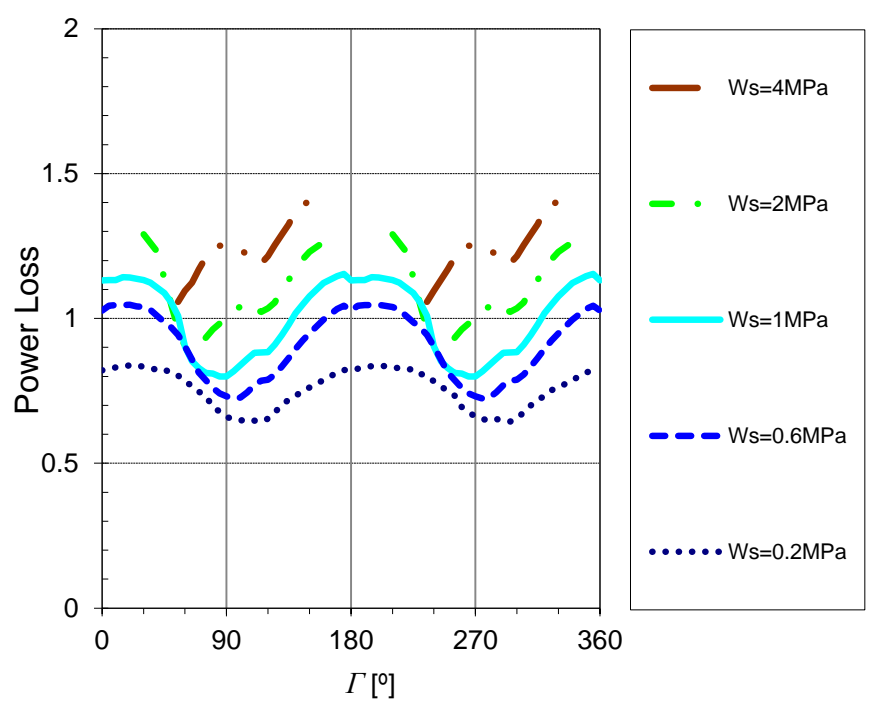

(b)

Fig 10 - Power Loss as a function of load angle for (a) a single groove and (b) a twin groove journal bearing. 


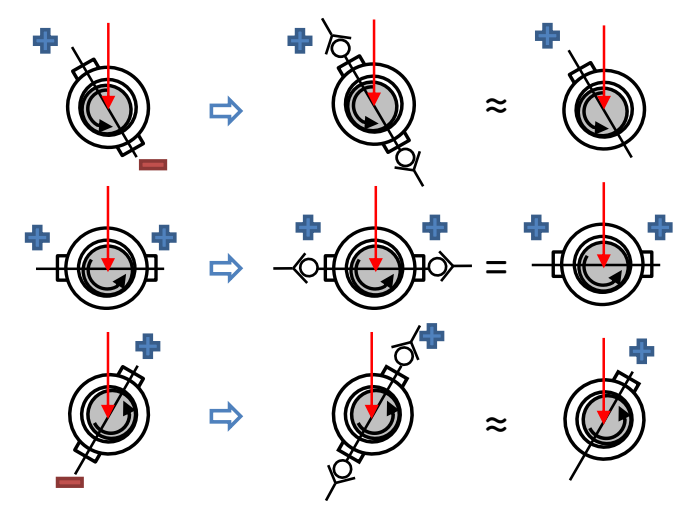

Fig 11 - Outline of check valve use to eliminate negative flow rate in a groove of twin groove bearings. Applying such a strategy would be similar to substituting a twin groove bearing by a single groove bearing with only the positive flow rate groove being used in this bearing. 


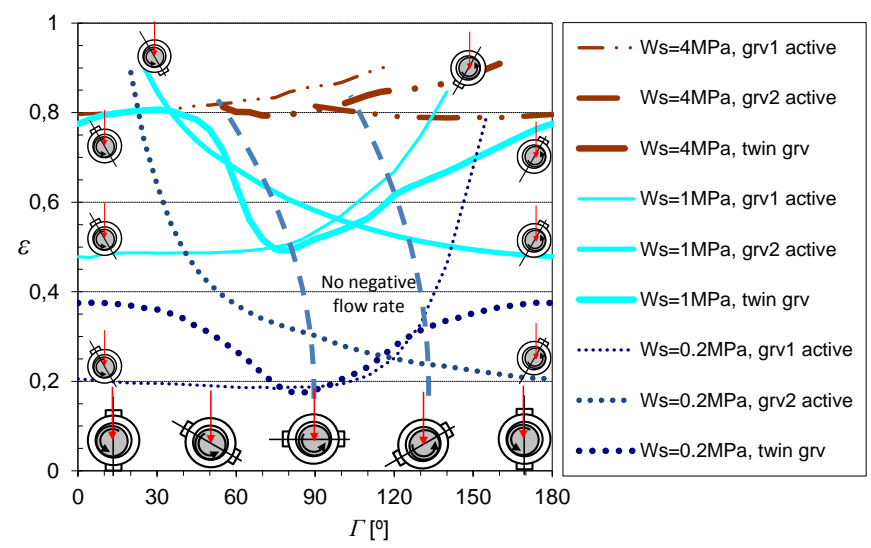

(a)

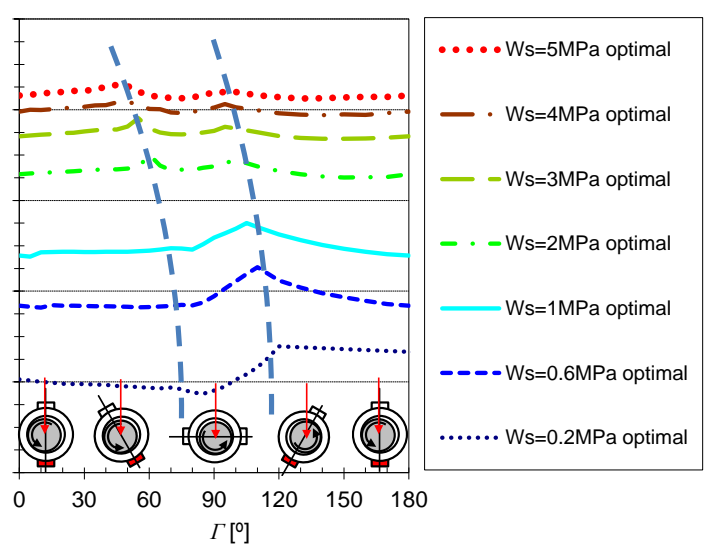

(b)

Fig 12 - Eccentricity ratio of (a) conventional single and twin groove bearings and (b) resulting unified eccentricity ratio graph of an idealized bearing which supresses the groove with negative flow rate. 


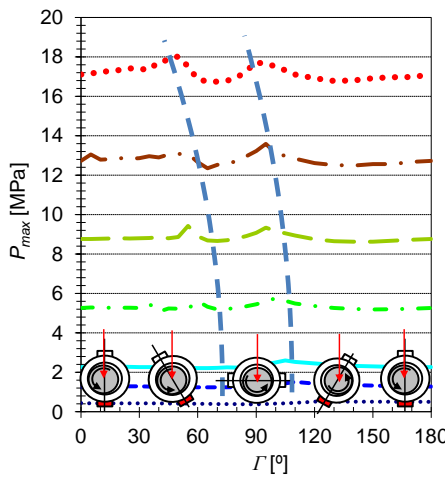

(a)

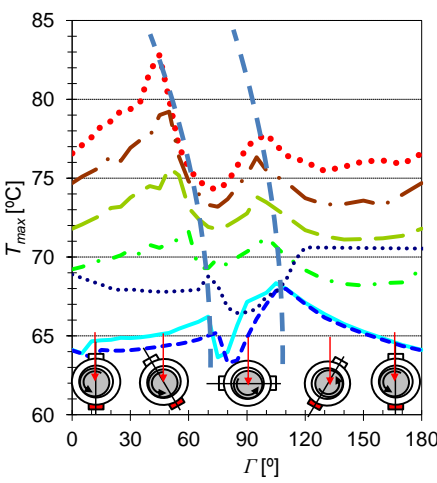

(b)

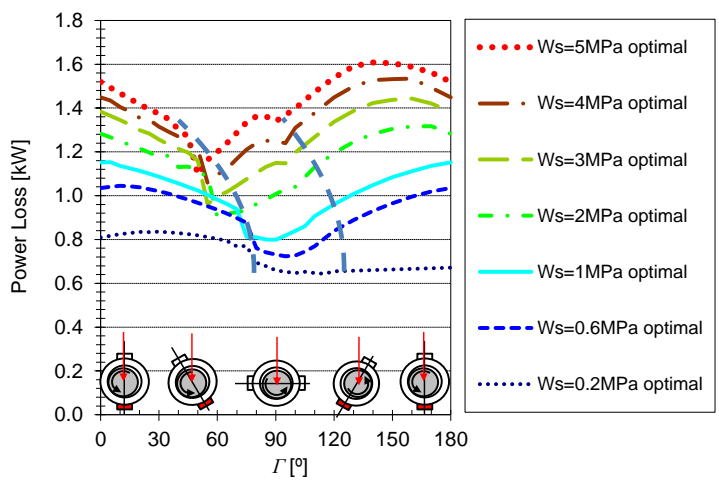

(c)

Fig 13 - (a) maximum pressure, (b) maximum bush temperature and (c) power loss of an idealized bearing which supresses the groove with negative flow rate. 


\begin{tabular}{|c|c|c|c|}
\hline Geometric characteristics & & Units & Default Value / Range \\
\hline - Inner bush diameter (nominal) & $d$ & $m m$ & 100 \\
\hline - Outer Bush diameter & $D$ & $\mathrm{~mm}$ & 200 \\
\hline - Bush width / diameter ratio & $b / d$ & & 0.8 \\
\hline - Groove number & & & $1 / 2$ \\
\hline - Groove angle with load line & & & $0^{\circ}-360^{\circ}$ \\
\hline - Groove lenght / bush length ratio & $a / b$ & & 0.875 \\
\hline - Groove width / diam. ratio & $w / d$ & & 0.18 \\
\hline - Bearing radial clearance (at $20^{\circ} \mathrm{C}$ ) & $C_{r}$ & $\mu m$ & 75 \\
\hline \multicolumn{4}{|c|}{ Operating and feeding conditions } \\
\hline - Rotational speed & $N$ & rpm & 3000 \\
\hline - Specific load range (approx). & Ws & $M P a$ & $0.2-10$ \\
\hline - Oil feeding pressure & $P_{f}$ & $k P a$ & 100 \\
\hline - Oil feeding temperature & $T_{f}$ & ${ }^{\circ} \mathrm{C}$ & 40 \\
\hline Lubricant properties & & & Value \\
\hline - T1 & & ${ }^{\circ} \mathrm{C}$ & 40 \\
\hline$-\mathrm{T2}$ & & ${ }^{\circ} \mathrm{C}$ & 70 \\
\hline - Dynamic viscosity @ T1 & $\mu_{T 1}$ & Pa.s & 0.0293 \\
\hline - Dynamic viscosity @ T2 & $\mu_{T 2}$ & Pa.s & 0.0111 \\
\hline - Specific Heat & $C_{p}$ & $\mathrm{~J} / \mathrm{kgK}$ & 2000 \\
\hline - Density & $\rho$ & $\mathrm{kg} / \mathrm{m}^{3}$ & 870 \\
\hline - Thermal conductivity & $k$ & $\mathrm{~W} / \mathrm{mK}$ & 0.13 \\
\hline
\end{tabular}

Tab 1 - Bearing geometric characteristics, operating and feeding conditions and lubricant properties used in the simulations. 
Graphical abstract
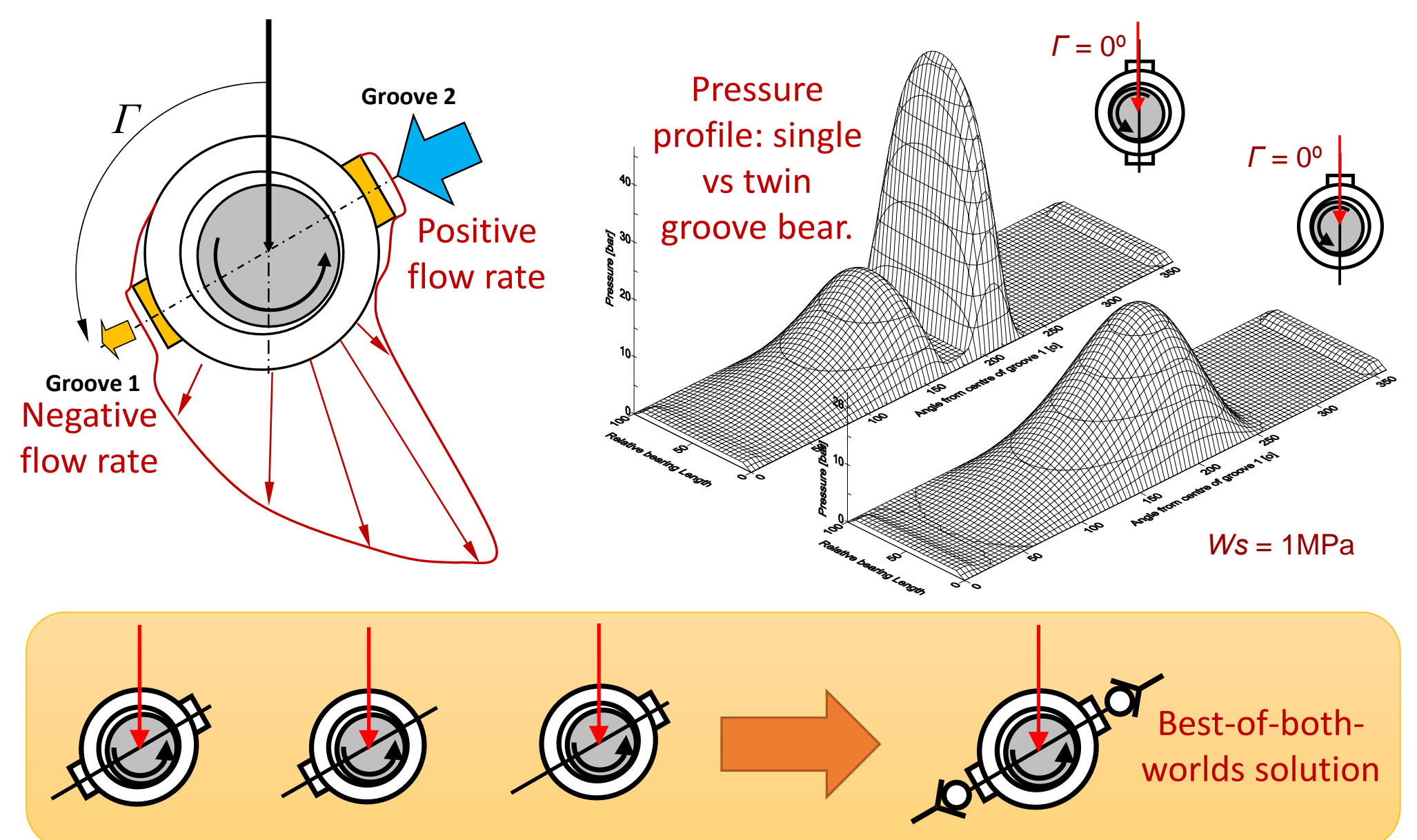